\title{
Evaluation of Bond Strength of Surface Conditioned Artificial Teeth with Modified and Valplast Denture Bases With Aging \\ Hikmat Jameel Aljudy
}

B.D.S., M.Sc., Ph.D. Assistant professor, Prosthodontics Department, College of Dentistry, University of Baghdad.

Ali Nima Ahmed Hussein

B.D.S., M.Sc. Lecturer, Prosthodontics Department, College of Dentistry, University of Baghdad.

IhabNabeel Safi

B.D.S., M.Sc. Lecturer, Prosthodontics Department, College of Dentistry, University of Baghdad.

\begin{abstract}
Background: bond failure of acrylic and porcelain teeth represents primary clinical disadvantages of partial and complete denture services provided to the patient. The aims of the study were to investigate the tensile and shear bond strength of two types of denture bases (heat cured reinforced with $\mathbf{5 \%} \mathrm{ZrO}_{2}$ nano-fillers and valplast) with (acrylic and porcelain) teeth after ridge lap conditioning and using aging. The measurements were used for comparison with traditional denture base.

Materials and methods: denture bases reinforced with nano $\mathrm{ZrO}_{2}$ and valplast were bonded to acrylic and porcelain teeth. Samples were divided for shear and tensile strength. Each contains 5 samples. The ridge lap surface were conditioned by different treatments and then subjected to aging. Tensile and shear bond strength measured by instron testing device. The results were organized and evaluated by using analysis of variance ( $f$-test) and t-test for comparison between subgroups.

Results: artificial teeth bonded to nano reinforced denture base required higher tensile and shear force to separate when compared with traditional heat cured and valplast resins. The mode of failure where cohesive either in the denture base or in the tooth itself when compared with valplast resin. Acrylic teeth conditioned with turpentine and porcelain with hydrofluoric acid express higher tensile and shear bond compared with unconditioned teeth. Aging sustained damaging effects on the bond strength of artificial teeth bonded to valplast denture base in compared with nano reinforced and conventional heat cured.

Conclusions: tensile and shear bond strength of artificial teeth enhanced by the reinforcement of the resin with nano-sized fillers and by conditioning of the teeth ridge lap using chemical agents, making the bond stronger and durable to withstand fluctuated oral conditions.
\end{abstract}

KEY WORDS

Nano reinforced, valplast, porcelain teeth, turpentine, tensile bond strength.

CITE THIS ARTCLE:

Aljudy H, Hussein A,Safi I. Evaluation of Bond Strength of Surface Conditioned Artificial Teeth with Modified and Valplast Denture Bases With Aging. Iraqi Dent. J. 2015; 37(3):97-106. http://www.iraqidentaljournal.com

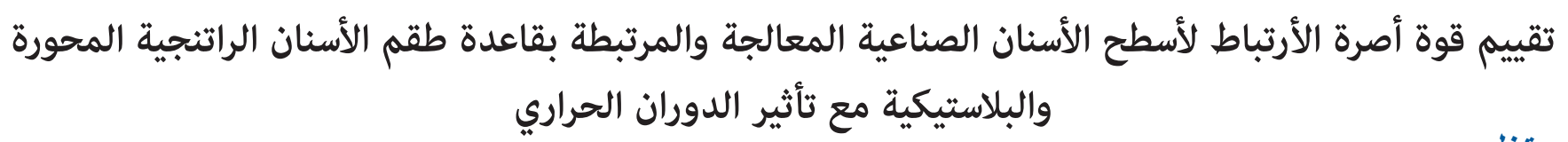

$$
\text { والبلاستيكية مع تأثير الدوران الحراري }
$$

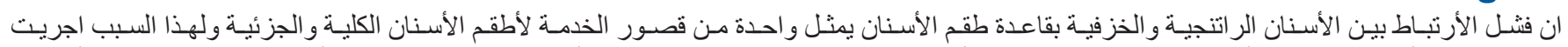

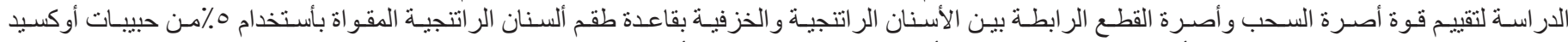

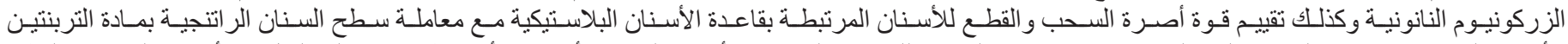

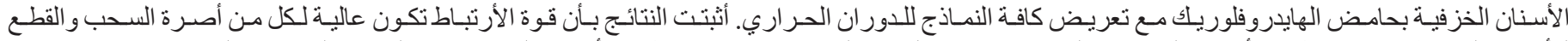

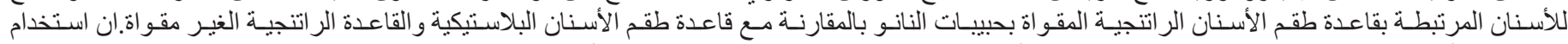

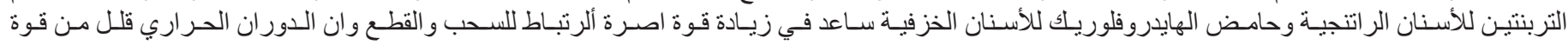

\section{INTRODUCTION}

Separation of teeth from denture bases is one of the essential clinical and laboratory challenges faced the prosthodontist, technician and patient ${ }^{(1)}$.

Many factors contribute for such fracture such as: denture iatrogenic impact, higher force during mastication, long term use excessive fatigue ${ }^{(2)}$.While in the lab, bond failed by weak technical approach leads to subsequent failure, presence of wax remnants or separating medium on the ridge lap leads to poor bond ${ }^{(3)}$. On the other hand, the presence of higher amount of cross linking agent added to the resin matrix of acrylic teeth leads to weak bond, in addition to the availability of free monomer transfer during curing of the resin base play important role in the durability of the bond strength ${ }^{(3,4)}$.

Ridge lap chemical conditioning using organic

$$
\text { الأرتبـاط لكلا النوعين من الأسنان وقاعدة طقم الأسنان. }
$$

compounds found to be effective in improving the tensile, ${ }^{(4)}$ and shear bond strength ${ }^{(5)}$.On the other hand, sand blasting porcelain teeth ridge lap with aluminum oxide decreasing the shear and tensile bond strength especially after aging ${ }^{(6)}$.

Patient acceptance for partial and complete dentures had no statistical difference between acrylic and porcelain teeth ${ }^{(7,8)}$.

Water bath resin had higher shear and tensile bond with both types of artificial teeth. On the other hand, mechanical retention and intimate contact plays vital role in the bond strength between teeth and flexible resin base $^{(9)}$. Addition of nano-fillers to resin resulted in higher bond of fillers and resin molecules that enhance the shear and tensile bond strength. So internal stresses wouldn't deteriorate that bond ${ }^{(10)}$.

Aging used in vitro environment to generate 


\section{Prosthodontics}

thermal changes similar to the oral cavity ${ }^{(11)}$. The normal temperature changes that human being can withstand was ranged $\left(0-68 \mathrm{C}^{\circ}\right)^{(12)}$. The basic idea of aging is periodic contraction and swelling creates stress inside the materials ${ }^{(13)}$. Which will affects the longevity of the prosthesis service and deteriorates the bond between denture bases and teeth ${ }^{(14)}$. Stress formation will expose the materials to temperature impact and leads to minor (cracks) ${ }^{(15)}$. Therefore; the purposes of this study are to estimate the tensile and shear bond strength of (heat cured with $5 \% \mathrm{ZrO}_{2}$ nanofillers and valplast) with acrylic and porcelain teeth) and effects of ridge lap conditioning with turpentine for acrylic and hydrofluoric acid for porcelain teeth. In addition; effect of aging on that bond strengths.

\section{MATERIALS AND METHOD}

The planned number of the samples which prepared for this study was 240 and organized by the selection of 120 upper central incisors for the shear bond strength and another 120 upper first molars for the tensile bond strength. For every test there were 60 acrylic (Florident, china) and 60 porcelain teeth (Ivoclar, vivadent) which were waxed either onto the beveled surface of a rectangular wax block with dimensions of $(17,10,5$ and $9 \mathrm{~mm})$ for the length, width, thickness and length of bevel side respectively, according to the Japanese standard for artificial teeth (JIST 6506, 1989) for shear bond strength test or attached to waxed arms representing the both ends of the tensile sample while the tooth represent the central part of that sample dimensions of $(75,12,6$ and $30 \mathrm{~mm}$ ) for the length, width, thickness and internal length respectively according to ADA specification No.15 ${ }^{(16,21)}$. As shown in Figure 1.
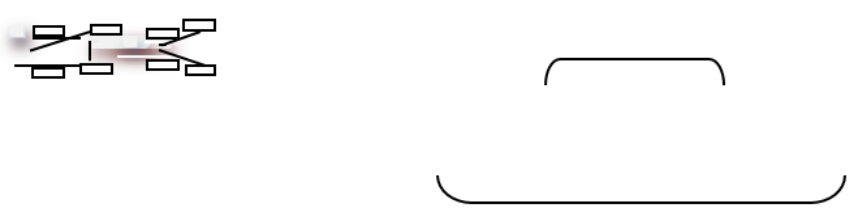

(A)

Figure 1: A; the samples configuration and dimensions for shear bond strength, B; the samples configuration and dimensions for tensile bond strength.

For the tensile bond strength testing; the four axial (lateral) surfaces of both acrylic and porcelain teeth were trimmed by machining in trimmer machine to the diameter of $6 \mathrm{~mm}$ and $5 \mathrm{~mm}$ length in order to obtain the final shape of cylinder suitable for tensile sample according to ADA specification No. 15. Also for the porcelain molar teeth and in order to creates a diatoric preparation on the both bonding surfaces a $2 \mathrm{~mm}$ groove were drilled on both sides of the porcelain tooth by using diamond bur and the depth of the drilling were controlled by using rubber stopper as illustrated in Figure 2.

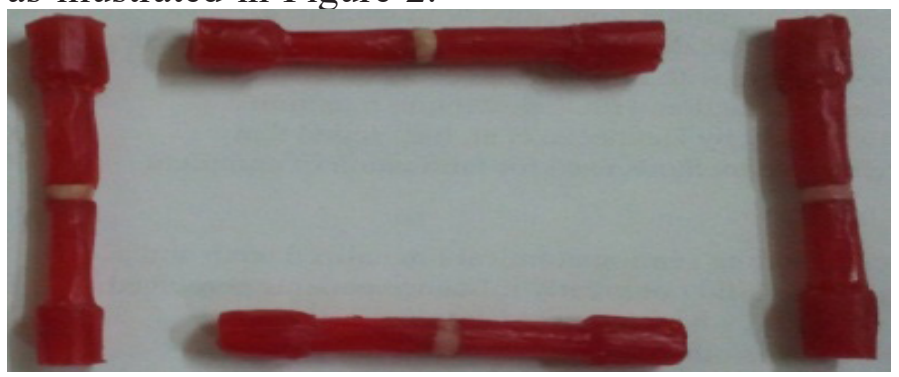

Figure 2: the wax blocks for acrylic teeth tensile test.

\section{Teeth conditioning:}

For both acrylic and porcelain teeth the ridge lap was conditioned by chemical materials: turpentine (Dyna- Coat Thinner Standard, Product of Netherlands) for acrylic and hydrofluoric acid (Thomas baker India HF Analyzer) for porcelain teeth. They were applied by sponge applicator for (180 seconds) and access removed by cotton rolls.

\section{Preparation of stone mould for tests samples:}

The acrylic and porcelain teeth were attached to wax patterns represents the samples for both tests. These samples were covered with separating medium (Vaseline petroleum jelly, Germany) and left aside to dry. Then type III dental stone (Elite model, Italy) in amount of $120 \mathrm{gm}$ was mixed according to manufacturer recommendation and the mixing slurry was poured into a metallic flask (BRODEN, Sweden) lower half, after that the samples were placed inside the slurry stone by covering approximately half of the samples and exposing the other half, then they left until the stone sets, as illustrated in figure 3 .

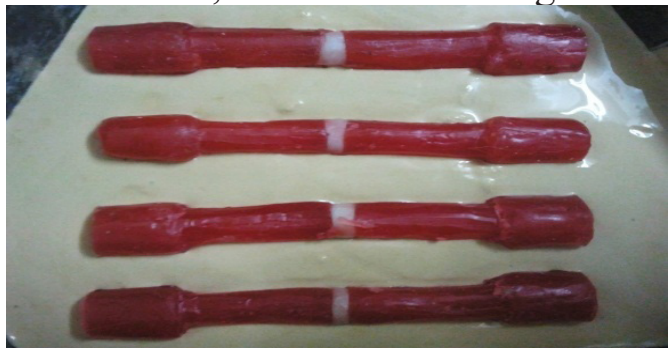

Figure 3: the waxed samples for tensile test embedded in the lower half of the flask.

In case of flexible samples, two types of special sprues were selected and as follows: $6-8 \mathrm{~mm}$ in diameter major sprues and $2-4 \mathrm{~mm}$ minor sprues. These sprues assembled to specific areas of the waxed samples and from one side only ${ }^{(17)}$.After that, 
the upper half of the metallic flask was placed on the lower half and then $300 \mathrm{gm}$ of slurry stone were poured. During stone pouring dental vibrator (Quayle Dental, England) was used in order to eliminate the air bubbles. The flasks were left until the stone set before wax elimination and flask opening.

Wax was eliminated by placing the metal flasks in a water bath (EWL 55 01, West Germany) with boiling water for 15 minutes. For the shear bond test samples, the teeth were left in the stone of the upper half of the flask and the mould cavity was present in the lower half. While for the tensile bond test samples, the teeth was attached to the lower half while the mould cavity was divided between the upper and lower halves of the flask. The mould cavity was gently washed and cleaned.

\section{Manipulation of denture bases:}

a.Nano reinforced acrylic resin:

First step: Silane surface treatment of $\left(\mathrm{ZrO}_{2}\right)$ nanofillers:

The application of silane reactive groups to the fillers surface were done with the addition of the 3-trimethoxysilylpropylmethacrylate, TMSPM, (Sigma Aldrich, Germany) to the nano-fillers of zirconium oxide (Sigma-Aldrich Germany). And this addition was achieved by mixing of: $200 \mathrm{ml}$ toluene solvent in pure state with $30 \mathrm{~g}$ of nano $\mathrm{ZrO}_{2}$ fillers and the mixture were placed into a flask made from a glass. Then the mixture was vibrated by ultrasonication at $\left(37 C^{\circ}\right)$ of room temperature for about $20 \mathrm{~min}$. then, the mixture of filler and toluene were poured into a special flask supplied with a magnetic stirrer (labinco, bv model l-81) at (37C) of room temperature. After that, 1.5 gm of TMSPM which represent ( $5 \%$ wt to $\mathbf{Z r O}$ ) was mixed gradually drop by drop from sterile syringe under fast stirrering. The flask was enveloped by using a mixture of parafilm with the slurry and placed without movement in the flask for 48 hours. At the end of this period the toluene solvent was eliminated by rotary evaporator (RE 510, Yamato, Japan) of $150 \mathrm{rpm}$ with vacuum for $30 \mathrm{~min}$ at $60^{\circ} \mathrm{C}$. At the end of this procedure, the surface treated $\mathrm{ZrO}_{2}$ nano-filler became silanated so they were placed in vacuum oven (Gallenbamp, England) for 20 hours at $60 \mathrm{C}^{\circ}$ to obtain dryness then the nano $\mathrm{ZrO}_{2}$ filler were preserved at $37 \mathrm{C}^{\circ}$ of room temperature until use ${ }^{(18)}$

\section{Second step: Measuring of acrylic and nanofillers} incorporation:

The addition of surface treated $\mathrm{ZrO}_{2}$ nano-filler were done by using an electronic balance (Sartorius
BP 30155, Germany) with accuracy of (0.0001 $\mathrm{gm})$ to $6 \mathrm{ml}$ of monomer liquid by taking $5 \%$ by weight, this ratio represent $0.600 \mathrm{~g}$ of silanated nano $\mathrm{ZrO}_{2}$. For better spreading the nano-fillers in the monomer, application of ultra sonication technique and this is done by using a probe sonication apparatus was used (Soniprep-150, England) at $120 \mathrm{~W}, 60 \mathrm{KHz}$ for duration of 3 minutes in order to separate them into individual nano-particles. The mixture of the nanofiller and monomer were added quickly to $11.400 \mathrm{~g}$ of powder acrylic (Spofa Dental Czechoslovakia) in order to decrease the chances of filler particle precipitation and detachment of the two phases. The $\mathrm{P} / \mathrm{L}$ ratio for the mixing of acrylic resin was (12 gm: $6 \mathbf{m l}$ ). the manipulation procedure were done immediately, in a mixing jar which were clean and dry by using a clean wax knife for a duration of half minute. The mixture was then left in covered jar in order to reach the dough stage for the acrylic resin. After that the mixture were taken and placed in the mould space of the metallic flask for resin packing ${ }^{(19)}$.

After that the metallic flasks were placed in a water bath device which was sets for a temperature of $73 \mathrm{C}^{\circ}$ for about 1.5 hours. Then gradually increasing the temperature to a boiling point at $100 \mathrm{C}^{\circ}$ and keeping this temperature for half an hour ${ }^{(20)}$.

b. TheValplast denture base:

The process begins with raising the temperature cylinder placed inside a cavity found inside an electrically operated furnace to allow it to heats up until reaching the intended temperature which is about $287 \mathrm{C}^{\circ}$. Then the warmed cylinder taken from the furnace. The cartridge for valplast resin (flexible nylon granules valplast international corporation, US A) placed inside the warming cylinder both were inserted inside the furnace for about 11 minutes in order to make the valplast granules in the metallic cartridge melt. Mean while, the metallic flask which were placed inside the oven for a preheating for 30 minutes at $65 \mathrm{C}^{\circ}$. After that, the flask was taken from the oven and inserted in the injection unit (Plastic injection system, vertex company) and oriented horizontally in exact place with the help of metal extension found at the base of the injection unit, this to place the injection opening which present at the upper place of the metallic flask. The dvmaterials were introduced inside the cavity mold of the metallic flask.

By the application of a manual pressure, the heating unit handles were secured to the degree that would make sure that a pressure of 5 bars was applied and detected by the closure of both springs 
on the top side of the unit. After a period of 5 minutes the applied pressure was removed and the flask was taken from the heating unit and left to cool down at room temperature. Then de-flasking was done and the samples were taken from the flask ${ }^{(17)}$.

Conditioning of the samples, finishing and polishing:

A cutoff disc were used to cut the sprues of the samples with the application of a light pressure and water cooling in order to prevent excessive heating of the samples, then the samples borders were cut by using grinding wheel rotated at $1500(\mathrm{rpm})$. After that the samples were finished by hand using silicon carbide paper bur with finer grades of about (120500) $)^{(21)}$.

\section{Storage of the samples:}

The samples were kept at $37 \mathrm{C}^{\circ}$ for one week before tensile and shear testing. After that the first half of the samples were subjected to tensile and shear tests by using universal testing machine (Instron Corporation, canton mass). The second half of the samples were subjected to thermo cycling by using special device (Haackt, Germany) of temperature ranging between $\left(\mathbf{5} \mathrm{C}^{\circ}\right.$ and $\mathbf{5 5} \mathrm{C}^{\circ}$ ) in one minutes cycle for about 3 days which represent 1000 cycle $^{(22)}$.

Shear load was applied at 45 degrees from the long axis of each denture tooth on the palatal surface at a cross head speed of $0.5 \mathrm{~mm} / \mathrm{min}$ until fracture ${ }^{(8)}$, while for the tensile test the load was applied at a cross head speed of $1 \mathrm{~mm} / \mathrm{min}$ until fracture ${ }^{(23)}$.

In all the samples tested, the fractured sites were examined. The joint failure was divided as being either adhesive or cohesive.

The tensile and shear bond strength was recorded as follows: $(\boldsymbol{B S})=\mathrm{F} / \mathrm{S}$ where $(\boldsymbol{B S})$ is the bond strength in $\left(\mathbf{N} / \mathbf{m m}^{2}\right)$ or Mpa and $\mathrm{F}$ is the force at fracture in $(N)$ and $\mathrm{S}$ is the surface area in $\left(\mathbf{m m}^{2}\right)^{(8)}$.

The surface area $(\mathrm{S})$ where calculated as follows: $S=\pi / 4 * D^{2}$ where $M=22 / 7$ or 3.14 and $D$ is the diameter of the bonded tooth which is $5 \mathrm{~mm}$ for shear test and $6 \mathrm{~mm}$ for tensile test so, $\mathrm{S}=19.64 \mathrm{~mm}^{2}$ in the shear test and $28.26 \mathrm{~mm}^{2}$ for the tensile test ${ }^{(8,23)}$.

The obtained data were statistically organized by the application of analysis of variance (ANOVA) of the three ways type. Also t-test for comparison between groups where applied, in addition to the means and standards deviations.

\section{RESULTS}

The data of the tensile and shear bond strength were expressed as means in Mpa and illustrated in figure 4 which shows the acrylic teeth data while figure 5 represent porcelain teeth and both of them were bonded to heat, valplast and nano-reinforced acrylic resin. The analysis of variance (ANOVA) showed a highly significant difference in the shear and tensile bond strength between surface conditioning, type of denture base and thermo cycling $(\boldsymbol{P}<\mathbf{0 . 0 0 1})$. A significantly higher difference in both types of artificial teeth and surface conditioning and denture bases with interactions between them $(\boldsymbol{P}<\mathbf{0 . 0 0 1})$ as illustrated in table 1.

\section{The variables of the study:}

3.Effect of artificial teeth conditioning:

The student t-test for surface conditioning showed that the artificial teeth (acrylic and porcelain) expressed significantly higher shear and tensile bond strength when compared with the control group $(\boldsymbol{P}<\mathbf{0 . 0 0 1})$. The exception where the valplast denture bases were used. The conditioning with turpentine in acrylic and hydrofluoric acid in porcelain teeth were significantly beneficial in increasing the tensile and shear bond strength of the all kinds of denture bases for both situations before and after thermocycling and as expressed in tables 2 and 3 .

4.Denture base materials used in the study:

The data showed that the nano reinforced denture bases and conventional heat polymerized denture bases expressed significantly higher tensile and shear bond strength when compared with the valplast denture base, with the exception for porcelain teeth where t-test showed no significant differences as illustrated in tables 4,5,6,7.

\section{Effect of thermocycling:}

The student t-test revealed that the tensile and shear bond strength of control group in conventional heat polymerized resin was not significantly influenced by thermocycling $(\boldsymbol{P}>0.05)$ also the data showed that thermo cycling had no significant effect on tensile and shear bond strength $(\boldsymbol{P}>\mathbf{0 . 0 5})$ for both artificial teeth bonded to nano-reinforced acrylic resin. On the other hand, thermo cycling showed significant influence on the tensile and shear bond strength of artificial teeth bonded to valplast denture bases $(\boldsymbol{P}<\mathbf{0 . 0 5})$ and this was illustrated in tables 8,9,10and figures 4,5, 6 and 7.

The microscopic examination of the conditioned surfaces of acrylic and porcelain teeth revealed that acrylic teeth conditioned with turpentine showed micro-roughness with pits and pores. On the other hand, porcelain teeth conditioned with hydrofluoric acid showed increase in the roughness and disappearance of surface glaze. 


\section{DISCUSSION}

The results of the study were classified into groups depending on the artificial teeth conditioning, types of denture bases used and thermo cycling technique applied.

\section{Surface conditioning of the artificial teeth:}

The surface conditioning of acrylic teeth by turpentine and porcelain teeth by hydrofluoric acid resulted in improving the tensile and shear bond strength. The organic solvent (turpentine) is a multi solvents, resulted in washing away the micro remnants of acrylic resin and smoothing the tooth surface and resulted in formation of three dimensional perforated pattern (sponge) and increasing the bonding sites with swelling of the resin polymer chain so improving the movement of the acrylic resin during polymerization from resin base to tooth resin. The durability of that bond directly proportional to the amount of diffusion of the organic solvents which depends on the amount and time of application. So by adequate time and amount the strength of the interwoven polymer network (IPN) formed will be more and the bond strength will be more too ${ }^{(24)}$.On the other hand, hydrofluoric acid application results in formation of microgrooves and pores results in formation of micro mechanical bond between the denture base resin and the conditioned porcelain tooth ${ }^{(25)}$.

\section{The type of denture bases:}

The valplast flexible resin appear to be unable to provide enough diffusion ability on the ridge lap surface of the tooth in order to provide strong bond which resulted from insufficient wetting of the flexible resin as a result of its higher viscosity and the lack of polymerizable resin spreading on the tooth surface because the material is being thermally molded directly in the denture shape ${ }^{(9)}$. On the other hand, the dissimilarity of the kind of the polymerization reaction between resin and teeth when valplast is used found to be incapable of supply the same amount of free monomer particles when compared with heat cured resin ${ }^{(17)}$. Also, the polymerization temperature of the heat cured resin is higher than valplast which resulted in an increase number and velocity of transfers of the free monomer to the swelling chains of the resin teeth resulted in a higher tensile and shear bond strength, in addition, the curing cycle of hot cured acrylic resin is longer in comparison with that of valplast so this leads to the formation of materials which had more molecular weight and durable bond strength between both the base and tooth polymer chains ${ }^{(23)}$.

For the nano-reinforced acrylic resin, the materials had very high interstitial bond formed between the resin matrix and the surface modified nano-fillers when compared with the ordinary hot cured resin, this strong bond were protect and guard the nano-fillers from external and internal stresses and provide higher interfacial bond strength so creating higher molecular weight polymer chains that are strongly packed and less susceptible to mechanical and thermal stresses ${ }^{(10)}$.

\section{Effect of thermocycling technique:}

There were higher similarity in the coefficient of thermal expansion between acrylic teeth and acrylic base which is about $\left(\mathbf{8 0 - 8 1} \times 10^{6} / \mathrm{C}^{\circ}\right)$ and for that reason there will be no chance for the creation of the thermal stress and the tensile and shear bond strength will not be affected by such thermal assault.On the other hand, the (control group) acrylic teeth which is very smooth and provide a good chance for adaptation of the resin base to the tooth ridge lap surface during acrylic packing, so reducing the possibility of porosity and voids formation ${ }^{(26)}$.On the other hand, surface conditioning with turpentine for the acrylic teeth leads to the formation of micro roughness and pitted surface due to the evaporation of the volatile turpentine and this was expressed during microscopic evaluation. These pores and voids diminished the opportunity for good adaptation of the resin base to the tooth ridge lap surface at the packing stage ${ }^{(23)}$.In additions, as the thermocycling causes increase in the water content of the samples so the water sorption of the materials will increase and this had a deleterious effect on the bond strength because the water molecules may accumulates into the area of the bond and percolates in the pores of the bonding sites resulting in a larger stress building at the bonding sites due to samples swelling ${ }^{(26)}$.

The valplast denture base is a brittle material when compared with the hot cured and nano- reinforced resin. So the valplast had more chances to develop micro-flows (cracks) as a result of both finishing and polishing in the lath machine and this is mechanical effect or by thermal stress in the thermocycling machine which results in the development and union of the cracks to a total failure of the valplast samples ${ }^{(17)}$.On contrary, the nano-reinforced denture bases were not vulnerable to such thermal assault with thermocycling due to the effect of the surface modified salinated fillers incorporated in the resin materials $^{(10)}$.

The porcelain teeth bonded to nano-reinforced resin base was not affected by thermocycling because these teeth depend on their metallic pins (for shear test) and diatoric grooves (for the tensile test) for bonding to the denture base. So the bond of the 


\section{Prosthodontics}

resin base to the ridge lap surface of porcelain teeth the additional thermal assault of the thermoycling minimally dependent on the adhesion of the resin technique, significant stresses were expected to base to the ridge lap surface so that additional thermal be building at the tooth resin base interface, so by stress by thermocycling will not affect the bond any cycling and continues enlargement and shrinkage at more(4).the dissimilarity in the coefficient of thermal the bonding joint will had significantly deleterious expansion between the resin base and porcelain teeth effects on the tensile and shear bond strength of was so obvious because for porcelain is was $\left(6.6 \times 10^{6} /\right.$ porcelain teeth to denture base ${ }^{(4,10)}$.

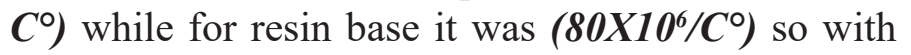

Table 1: ANOVA table for interactions of groups for both types of artificial teeth (acrylic and porcelain) attached to heat, valplast and nano reinforced denture bases.

\begin{tabular}{|c|c|c|c|c|}
\hline Groups & Bond & F-Test & P-Value & Significance \\
\hline \multirow{2}{*}{$\begin{array}{l}\text { Heat, valplas and nano reinforced denture bases bonded with acrylic } \\
\text { teeth } \\
\text { Control group }\end{array}$} & Shear & 32.99 & 0.003 & $\mathbf{S}$ \\
\hline & Tensile & 1.92 & 0.07 & NS \\
\hline \multirow{2}{*}{$\begin{array}{l}\text { Heat, valplast and nano reinforced denture bases bonded with acrylic } \\
\text { teeth } \\
\text { turpentine group }\end{array}$} & Shear & 61.32 & 0.001 & HS \\
\hline & Tensile & 1.88 & 0.09 & NS \\
\hline \multirow{2}{*}{$\begin{array}{l}\text { Heat, valplast and nano reinforced denture bases bonded with por- } \\
\text { celain teeth } \\
\text { Control group }\end{array}$} & Shear & 23.9 & 0.006 & $\mathbf{S}$ \\
\hline & Tensile & 23.46 & 0.001 & HS \\
\hline \multirow{2}{*}{$\begin{array}{l}\text { Heat, valplast and nano reinforced denture bases bonded with por- } \\
\text { celain teeth } \\
\text { Hydrofluoric acid group }\end{array}$} & Shear & 9.763 & 0.029 & $\mathbf{S}$ \\
\hline & Tensile & 14.92 & 0.001 & HS \\
\hline
\end{tabular}

Table 2: the student t-test for comparison between control and surface conditioning groups for acrylic teeth bonded to all denture bases before and after thermocycling.

\begin{tabular}{|c|c|c|c|c|}
\hline \multicolumn{5}{|c|}{ Heat cured denture base } \\
\hline Bond & Control\& Turpentine & $T$ test & P value & Significance \\
\hline \multirow{2}{*}{ Shear } & Before & 14.07 & 0.003 & $\mathbf{S}$ \\
\hline & After & 11.315 & 0.008 & $\mathbf{S}$ \\
\hline \multirow{2}{*}{ Tensile } & Before & 3.962 & 0.042 & $\mathbf{S}$ \\
\hline & After & 4.12 & 0.039 & $\mathbf{S}$ \\
\hline \multicolumn{5}{|c|}{ Valplast denture base } \\
\hline Bond & Controld Turpentine & $T$ test & Pvalue & Significance \\
\hline \multirow{2}{*}{ Shear } & Before & 0.896 & 0.465 & NS \\
\hline & After & 1.009 & 0.423 & NS \\
\hline \multirow{2}{*}{ Tensile } & Before & 0.96 & 0.832 & NS \\
\hline & After & 1.23 & 0.332 & NS \\
\hline \multicolumn{5}{|c|}{ Nano reinforced denture base } \\
\hline Bond & Control\& Turpentine & $T$ test & Pvalue & Significance \\
\hline \multirow{2}{*}{ Shear } & Before & 26.96 & 0.001 & HS \\
\hline & After & 113.21 & 0.001 & HS \\
\hline \multirow{2}{*}{ Tensile } & Before & 17.62 & 0.009 & $\mathbf{S}$ \\
\hline & After & 13.433 & 0.004 & $\mathbf{S}$ \\
\hline
\end{tabular}




\section{Prosthodontics}

Table 3: Student t-test for comparison between control and surface conditioning groups for porcelain teeth bonded to all denture bases before and after thermocycling.

\begin{tabular}{|c|c|c|c|c|}
\hline \multicolumn{5}{|c|}{ Heat cured denture base } \\
\hline Bond & Control\& hydrofluoric acid & $T$ test & Pvalue & Significance \\
\hline \multirow{2}{*}{ Shear } & Before & 4.27 & 0.051 & NS \\
\hline & After & 1.899 & 0.0198 & NS \\
\hline \multirow{2}{*}{ Tensile } & Before & 2.03 & 0.062 & NS \\
\hline & After & 1.989 & 0.078 & NS \\
\hline \multicolumn{5}{|c|}{ Valplast denture base } \\
\hline Bond & Control\& hydrofluoric acid & $T$ test & Pvalue & Significance \\
\hline \multirow{2}{*}{ Shear } & Before & 0.544 & 0.595 & NS \\
\hline & After & 0.516 & 0.269 & NS \\
\hline \multirow{2}{*}{ Tensile } & Before & 1.241 & 0.398 & NS \\
\hline & After & 0.98 & 0.889 & NS \\
\hline \multicolumn{5}{|c|}{ Nano reinforced denture base } \\
\hline Bond & Control\& hydrofluoric acid & $T$ test & Pvalue & Significance \\
\hline \multirow{2}{*}{ Shear } & Before & 12.32 & 0.007 & HS \\
\hline & After & 1.359 & 0.307 & NS \\
\hline \multirow{2}{*}{ Tensile } & Before & 2.43 & 0.049 & $\mathbf{S}$ \\
\hline & After & 2.39 & 0.048 & S \\
\hline
\end{tabular}

Table 4: student t-test for comparison between conventional heats, nano reinforced and valplast denture bases which were attached to acrylic teeth in control group before and after thermocycling.

\begin{tabular}{|c|c|c|c|c|c|c|c|}
\hline & & \multicolumn{3}{c|}{ Control before } & \multicolumn{3}{c|}{ Control after } \\
\hline Denture bases & Bond & T test & P value & Significance & T test & P value & Significance \\
\hline \multirow{2}{*}{$\begin{array}{c}\text { Heat and valplast denture bases } \\
\text { Heat and nano reinforced denture } \\
\text { bases }\end{array}$} & $\begin{array}{c}\text { Shear } \\
\text { Tensile }\end{array}$ & 5.47 & 0.032 & S & 5.75 & 0.029 & S \\
& $\begin{array}{c}\text { Shear } \\
\text { test }\end{array}$ & 0.134 & 0.038 & S & 2.68 & 0.042 & S \\
& Tensile & 3.89 & 0.028 & NS & 11.00 & 0.001 & HS \\
\hline \multirow{2}{*}{$\begin{array}{c}\text { valplast and nano reinforced den- } \\
\text { ture bases }\end{array}$} & Shear & 56.36 & 0.001 & HS & 33.89 & 0.001 & HS \\
& Tensile & 2.862 & 0.018 & S & 2.99 & 0.042 & S \\
\hline
\end{tabular}

Table 5: student t-test for comparison between conventional heats, nano reinforced and valplast denture bases which were attached to acrylic teeth in turpentine group before and after thermocycling.

\begin{tabular}{|c|c|c|c|c|c|c|c|}
\hline \multirow[b]{2}{*}{ Denture bases } & \multirow[b]{2}{*}{ Bond } & \multicolumn{3}{|c|}{ Turpentine before } & \multicolumn{3}{|c|}{ Turpentine after } \\
\hline & & $T$ test & Pvalue & Significance & $T$ test & Pvalue & Significance \\
\hline \multirow{2}{*}{$\begin{array}{l}\text { Heat and valplast denture } \\
\text { bases }\end{array}$} & Shear & 28.71 & 0.001 & HS & 24.25 & 0.002 & HS \\
\hline & Tensile & 82.6 & 0.001 & HS & 46.29 & 0.001 & HS \\
\hline \multirow{2}{*}{$\begin{array}{l}\text { Heat and nano reinforced } \\
\text { denture bases }\end{array}$} & Shear & 0.274 & 0.81 & NS & 1.229 & 0.344 & NS \\
\hline & Tensile & 34.68 & 0.001 & HS & 5.82 & 0.031 & $\mathbf{S}$ \\
\hline \multirow{2}{*}{$\begin{array}{l}\text { Valplas and nano reinforced } \\
\text { denture bases }\end{array}$} & Shear & 41.9 & 0.001 & HS & 26.93 & 0.001 & HS \\
\hline & Tensile & 4.68 & 0.039 & $\mathbf{S}$ & 13.89 & 0.001 & HS \\
\hline
\end{tabular}




\section{Prosthodontics}

Table 6: student t-test for comparison between conventional heats, nano reinforced and valplast denture bases attached to porcelain teeth in control before and after thermocycling.

\begin{tabular}{|c|c|c|c|c|c|c|}
\hline & \multicolumn{4}{c|}{ Heat cured before and after } \\
\cline { 2 - 8 } & \multicolumn{4}{|c|}{ Shear } & Tensile \\
\hline Control & T-Test & P-Value & Significance & T-Test & P-Value & Significance \\
\hline Turpentine & 2.001 & 0.18 & NS & 1.390 & 0.723 & NS \\
\hline Control & 21.16 & 0.002 & HS & 1.929 & 0.078 & NS \\
\hline Hydrofluoric acid & 4.00 & 0.049 & S & 1.46 & 0.134 & NS \\
\hline
\end{tabular}

Table 7: student t-test for comparison between conventional heats, nano reinforced and valplast denture bases attached to porcelain teeth in hydrofluoric acid before and after thermocycling.

\begin{tabular}{|c|c|c|c|c|c|c|c|}
\hline & & \multicolumn{3}{|c|}{ Control before } & \multicolumn{3}{|c|}{ Control after } \\
\hline Denture bases & Bond & $T$ test & Pvalue & Significance & $T$ test & Pvalue & Significance \\
\hline \multirow{2}{*}{ Heat and valplast denture bases } & Shear & 0.432 & 0.708 & NS & 4.935 & 0.039 & $\mathbf{S}$ \\
\hline & Tensile & 3.22 & 0.029 & $\mathbf{S}$ & 2.99 & 0.043 & $\mathbf{S}$ \\
\hline \multirow{2}{*}{$\begin{array}{l}\text { Heat and nano reinforced denture } \\
\text { bases }\end{array}$} & Shear & 4.106 & 0.048 & $\mathbf{S}$ & 1.306 & 0.305 & NS \\
\hline & Tensile & 1.82 & 0.092 & NS & 2.312 & 0.040 & $\mathbf{S}$ \\
\hline \multirow{2}{*}{$\begin{array}{l}\text { Valplast and nano reinforced denture } \\
\text { bases }\end{array}$} & Shear & 0.229 & 0.793 & NS & 4.863 & 0.041 & $\mathbf{S}$ \\
\hline & Tensile & 3.92 & 0.042 & $\mathbf{S}$ & 1.22 & 0.138 & NS \\
\hline
\end{tabular}

Table 8: comparison between experimental groups (t-test) for acrylic and porcelain teeth bonded to conventional heat cured before and after aging.

\begin{tabular}{|c|c|c|c|c|c|c|}
\hline & \multicolumn{4}{|c|}{ Nan reinforced denture bases before and after } \\
& T-Test & P-Value & Significance & T-Test & P-Value & Significance \\
\hline Control & 2.500 & 0.13 & NS & 1.84 & 0.098 & NS \\
Turpentine & 2.51 & 0.129 & NS & 0.103 & 0.893 & NS \\
\hline Control & 2.503 & 0.136 & NS & 0.119 & 0.723 & NS \\
\hline Hydrofluoric acid & 4.603 & 0.04 & S & 1.089 & 0.434 & NS \\
\hline
\end{tabular}

Table 9: comparison between experimental groups (t-test) for acrylic and porcelain teeth bonded to valplast denture base before and after aging.

\begin{tabular}{|c|c|c|c|c|c|c|c|}
\hline & \multicolumn{3}{|c|}{ Hydrofluoric acid before } & \multicolumn{3}{c|}{ Hydrofluoric acid after } \\
\hline Denture bases & Bond & T test & P value & Significance & T test & P value & Significance \\
\hline \multirow{2}{*}{ Heat and valplast denture bases } & Shear & 0.130 & 0.908 & NS & 4.225 & 0.049 & S \\
& Tensile & 3.268 & 0.042 & S & 2.126 & 0.049 & S \\
\hline $\begin{array}{c}\text { Heat and nano reinforced denture } \\
\text { bases }\end{array}$ & Shear & 0.986 & 0.908 & NS & 2.442 & 0.135 & NS \\
\hline & Tensile & 4.68 & 0.022 & S & 2.43 & 0.042 & S \\
\hline $\begin{array}{c}\text { Valplast and nano reinforced } \\
\text { denture bases }\end{array}$ & Shear & 0.564 & 0.629 & NS & 3.166 & 0.049 & S \\
\hline & Tensile & 4.296 & 0.026 & S & 1.862 & 0.093 & NS \\
\hline
\end{tabular}

Table 10: comparison between experimental groups (t-test) for acrylic and porcelain teeth bonded to nano reinforced denture base before and after thermocycling.

\begin{tabular}{|c|c|c|c|c|c|c|}
\hline \multicolumn{7}{|c|}{ Valplast denture bases before and after } \\
\hline & \multicolumn{3}{|c|}{ Shear } & \multicolumn{3}{|c|}{ Tensile } \\
\hline & T-Test & P-Value & Significance & T-Test & P-Value & Significance \\
\hline Control & 8.00 & 0.015 & $\mathbf{S}$ & 2.32 & 0.043 & $\mathbf{S}$ \\
\hline Turpentine & 7.001 & 0.020 & $\mathbf{S}$ & 2.93 & 0.041 & $\mathbf{S}$ \\
\hline Control & 17.20 & 0.003 & HS & 3.68 & 0.001 & HS \\
\hline Hydrofluoric acid & 5.778 & 0.029 & $\mathbf{S}$ & 3.23 & 0.038 & $\mathbf{S}$ \\
\hline
\end{tabular}




\section{Prosthodontics}

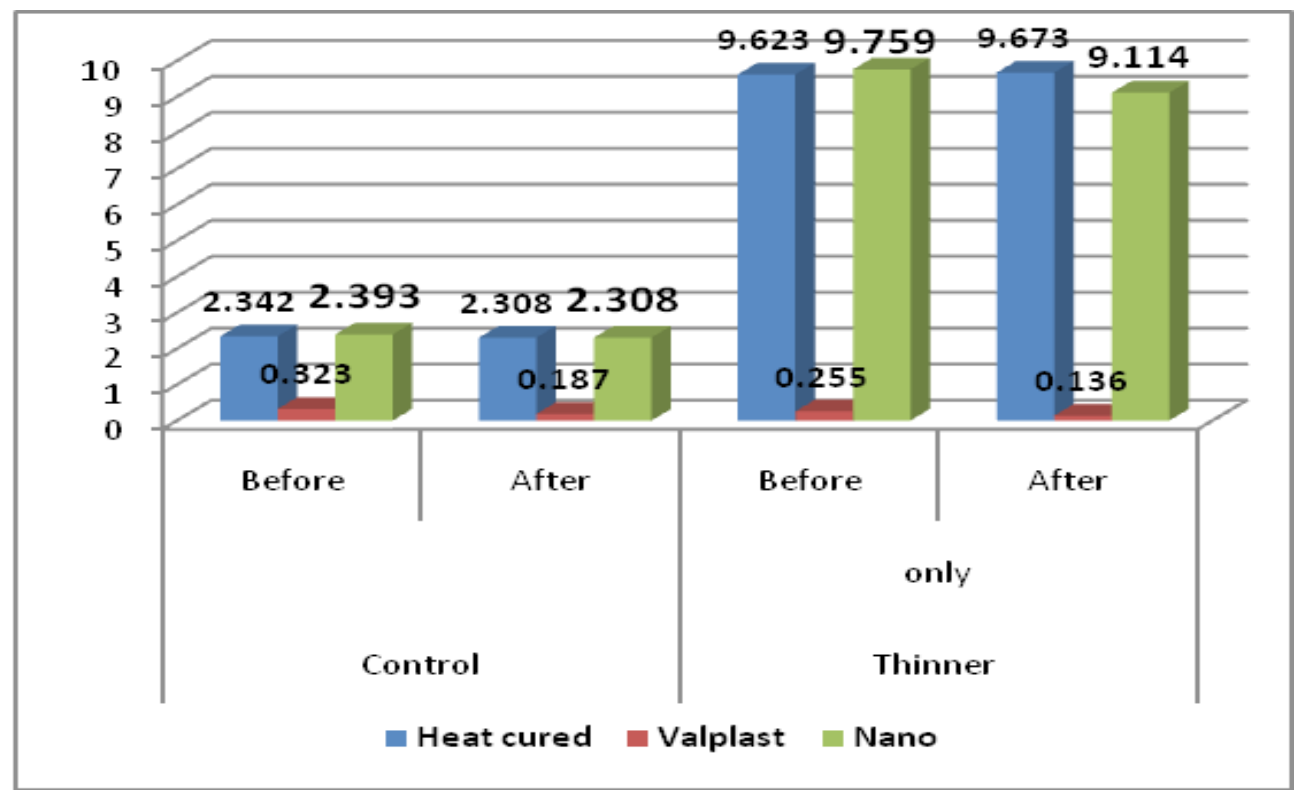

Figure 4: comparison of the mean values in Mpa for shear bond strength of acrylic teeth bonded to the denture bases before and after aging.

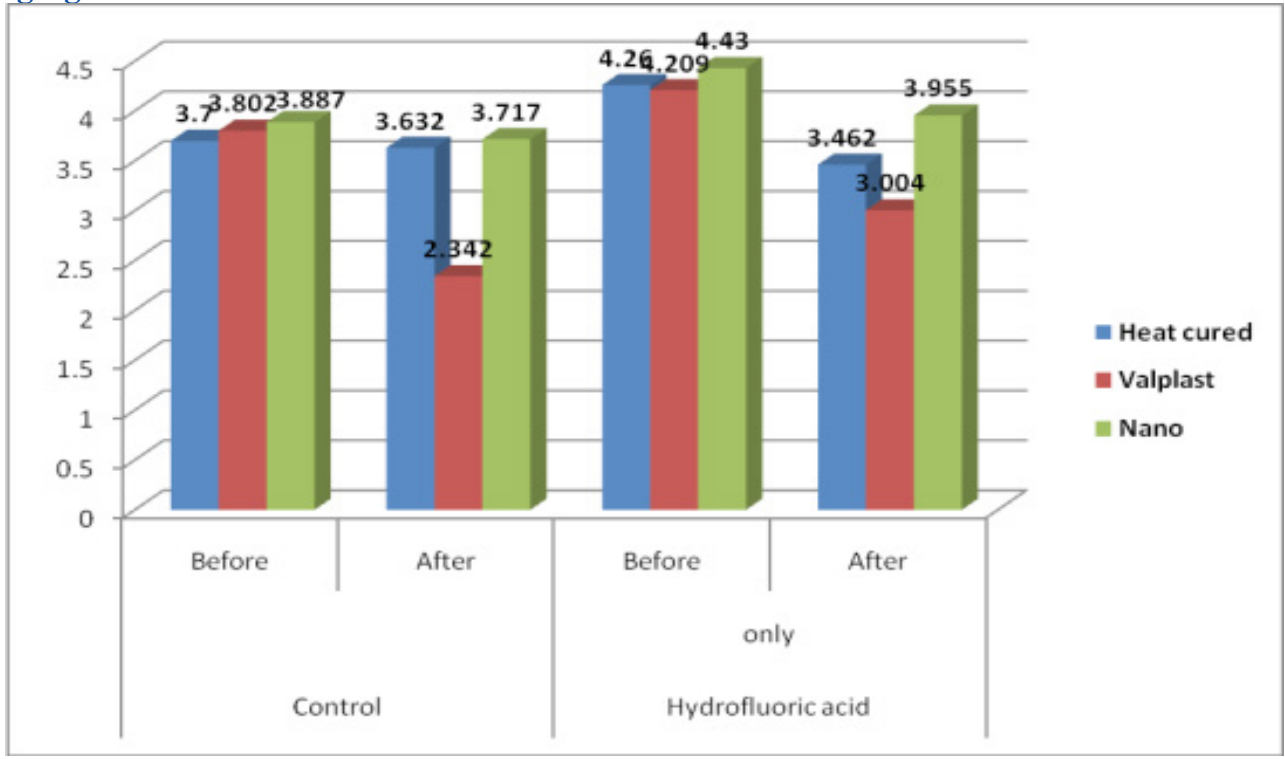

Figure 5: comparison of the mean values in Mpa for shear bond strength of porcelain teeth bonded to the denture bases before and after aging.

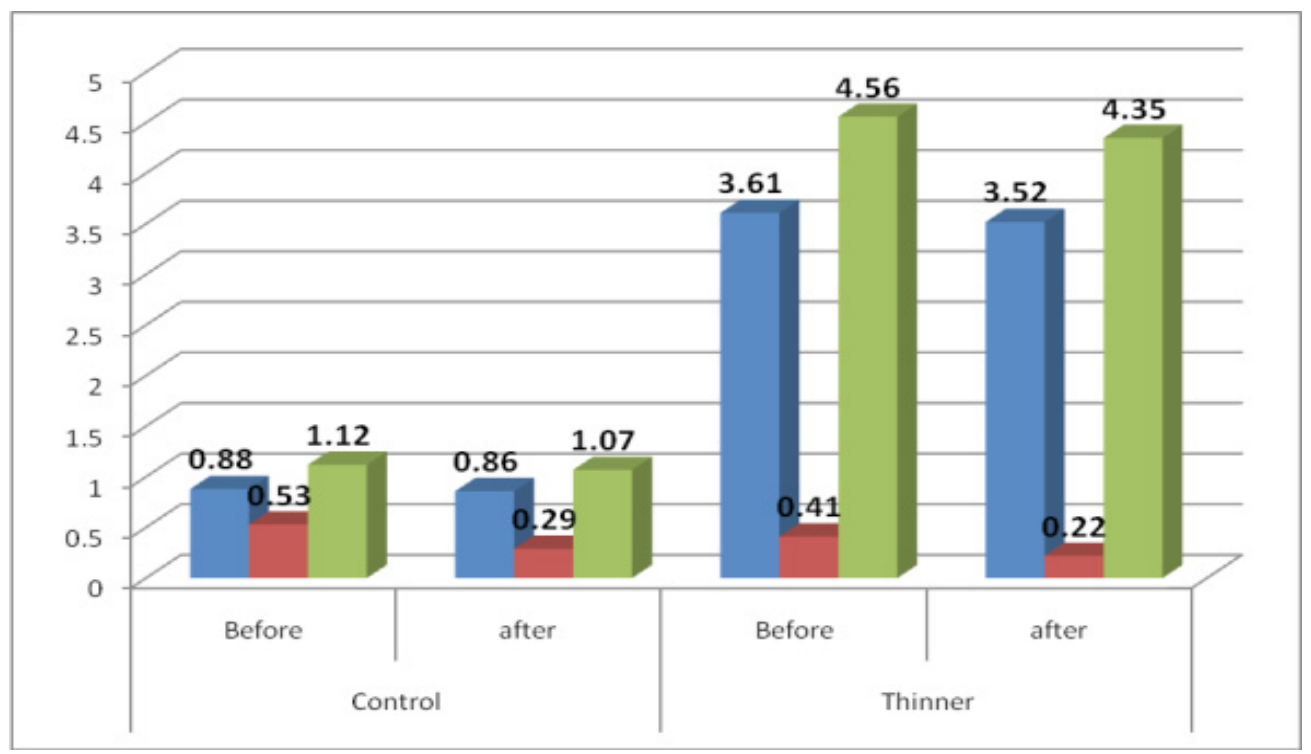

Figure 6: comparison of the mean values in Mpa for tensile bond strength of acrylic teethbonded to the experimental denture bases before and after aging. 


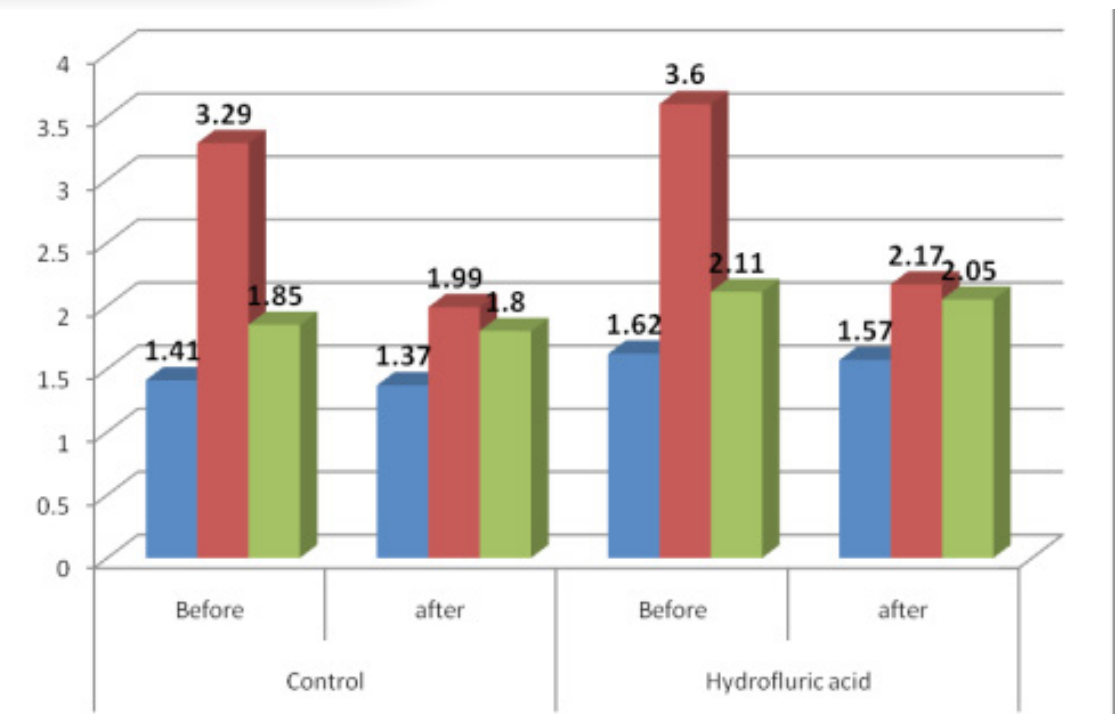

Figure 7: comparison of the mean values in Mpa for tensile bond strength of porcelain teeth bonded to the experimental denture bases before and after aging.

\section{REFERENCES}

1. Zukerman GR. A reliable method for securing anterior denture teeth in denture bases.J Prosthet Dent.2003; 89:603-7.

2. Vallittu PK and Ruyter IE.Swelling of PMMAresin at the repair joint.Int J Prosthodont. 1997; 10(3):254-58.

3. Cunningham JL,Benington IC.A survey of the pre-bonding preparation of denture teeth and the efficiency of de-waxing methods. J Dent. 1997; 25(2): 125-8.

4. Chai J, Takahashi Y, Takahashi T, Habu T. Bonding durability of conventional resinous denture teeth and highly cross linked denture teeth to a pour-type denture base resin." Int. J. Prosthodont. 2000; 13(2):112-6.

5. Huggett R, John G, Jagger RG, Bates JF. Strength of acrylic denture base tooth bond. Br Dent J. 1982; 153(5):187-90.

6. el-Sheikh MM, Powers JM. Tensile bond strength of porcelain teeth to denture resin before and after aging.Int $\mathrm{J}$ Prosthodont. 1998; 11(1): 16-20.

7. Cunningham JL. Bond strength of acrylic teeth to denture bases. J Dent. 1993; 21(5): 274-80.

8. Thean HP, Chew CL, Goh KI. Shear bond strength of denture teeth to base: a comparative study. Quintessence Int.1996; 27(6); 425-8.

9. Negrutiu M, Sinescu C, Romanu M, Pop D, Laktos S. Thermoplastic resins for flexible framework removable partial dentures. Temisoara Med J. 2005; 55: 295-9.

10. Atai M, Solhi L, Nodehi A, Mirabedini SM, Kasraei S, Akbari K, Babanzadeh S. PMMA-grafted nanoclay as novel filler for dental adhesives. Dent Mater. 2009; 25(3):339-47.

11. Saavedra G, Valandro LF, Leite FP, Amaral R, Ozcan M, Bottino MA, Kimpara ET. Bond strength of acrylic teeth to denture base resin after various surface conditioning methods before and after thermocycling.Int J Prosthodont. 2007; 20(2): 199-201.

12. Gale MS, Darvell BW. Thermal cycling procedures for laboratory testing of dental restorations. J Dent. 1999; 27(2):89-99.

13. Takahashi Y, Chai J, Kawaguchi M. Effect of water sorption on the resistance to plastic deformation of a denture base material relined with four different denture reline materials. Int J Prosthodont. 1998; 11(1):49-54.

14. Amin WM. Durability of acrylic tooth bond to polymeric denture base resins. Eur J ProsthodontRestor Dent. 2002; 10(2):57-61.
15. Neppelenbroek KH, Pavarina AC, Vergani CE, Giampaolo ET.Hardness of heat-polymerized acrylic resins after disinfection and long-term water immersion.JProsthet Dent. 2005; 93(2):171-6.

16. J.I.S.T 6506 (1989):” Acrylic resin teeth.” Japanese Standard Association, P: 16

17. Rizgar MA. A Ph.D. thesis.The effect of addition of radiopaque materials on some mechanical and physical properties of flexible denture base.Department of Prosthetic Dentistry, College of Dentistry, Hawler Medical University; 2009.

18. Ayad NM, Badawi MF, Fatah AA .Effect of reinforcement of high impact acrylic resin with micro-Zirconia on some physical and mechanical properties. Rev ClinPesqOdontol 2008; 4(3):145-51.

19. Shi J, Bao Y, Huang Z, Weng Z. Preparation of PMMANanomater calcium carbonate composites by in-situ emulsion polymerization. J Zhejiang University Sci. 2004; 5(6): 709-13.

20. Anusavice KJ. "Phillip's science of dental materials."10th Ed USA Philadelphia, WB, Saunders Co; 2008, p.: 211, 220, 235, 237-271.

21. American Dental Association, Specification No. 57, (2000). Chicago IL: ANSI/ADA.

22. Vergani CE, Machado AL, Giampaolo ET, Pavarina AC.Effect of surface treatment on the bond strength between composite resin and acrylic resin denture teeth.Int J Prosthodont. 2000: 13(5): 383-6.

23. Schneider RL, Curtis ER, Clancy JM. Tensile bond strength of acrylic resin denture teeth to a microwave- or heatprocessed denture base.J Prosthet Dent. 2002; 88(2):14550. (IVSL)

24. Delbert Trew. Coat oil was useful all-purpose home remedy. Texas Escapes Online Magazine. Blue Prints for Travel, LLC 2004; Ch4; P: 65.

25. Höland W, Schweiger M, Frank M, Rheinberger V. A comparison of the microstructure and properties of the IPS Empress 2 and the IPS Empress glass-ceramics. J Biomed Mater Res. 2000; 53(4):297-303. (IVSL)

26. Garcia RM, Léon BT, Oliveira VB, Del BelCury AA. Effect of denture cleanser on weight, surface roughness and tensile bond strength of two resilient denture liners.JProsthet Dent. 2003; 89(5):489-94. (IVSL) 